\title{
Analysis and Evaluation of Education Costs in Romania: Methods and Techniques
}

\author{
Anca Leontina PAPP (MARINESCU) \\ West University of Timisoara, Romania \\ E-mail: leoankm@gmail.com
}

Received date:28 January 2020; Accepted date:6 July 2020; Published date: 3 March 2021

Academic Editor: Răzvan Mihai Dobrescu

Copyright (C 2021. Anca Leontina PAPP (MARINESCU). Distributed under Creative Commons

Attribution 4.0 International CC-BY 4.0

\begin{abstract}
The cost of education may be the smallest monetary value belonging to the system inputs needed to reach a certain level of outputs. In order to understand the concept of cost of education, the notion of suitability of education must be understood in advance. There are two fundamental questions related to the educational adequacy concept: what is the amount of money that allows a school to provide its students with an adequate education and how the resources available in schools can be distributed so that all students receive an adequate education regardless of the circumstances in which the education process takes place. Through this paper, I want to identify answers to the two questions.

Keywords: Cost, education, cost analysis, cost evaluation, quality standards.
\end{abstract}

JEL Classification: $\mathrm{I}_{2}, \mathrm{I}_{25}$

\section{Introduction}

The Romanian educational system is financed from public funds which determine the acceptance of more responsibilities. It is impetuous to keep track of data that will allow performance evaluation from a managerial point of view as well as from the point of view of system outputs in society.

The outputs of the system are difficult to quantify financially because most of the

time the evaluation is done from the perspective of the knowledge acquired by the student evaluated through national exams and not necessarily from the point of view of its integration in production on the labour market.

The present paper presents the theoretical part and the functioning of the system.

\section{The Cost of Education and the Specific Costs of Education}

At a very general level, the cost of education represents the minimum amount of expenditures needed to provide the student society with a certain level of theoretical and practical training, 
considered appropriate (Andrews, $M$., Duncombe, W., Yinger, J. (2002) Revisiting economies of size in American education: are we any closer to a consensus? Economics of Education Review, no. 21, pp. 245-262).

The cost of education may be the smallest monetary value belonging to the system inputs needed to reach a certain level of outputs. In order to understand the concept of cost of education, the notion of suitability of education must be understood in advance.

The adequacy of education can be seen as an absolute measure of how sufficient funding levels can be offered to enable students to learn at a higher quality level (Picus, LO (2000) Adequate Funding, in About School Spending: American School Board Journal, p. 34). Taking into account the above, one can observe the difference between the suitability and the equity characteristics, which are concentrated on the relative levels of distribution of funds. The existence of an adequate funding system should allow the identification of the resources necessary for schools to ensure equal opportunities for students in achieving the quality standards existing at national level. Suitability should not be confused with equality, as students with special needs, for example, may need additional funds to reach the set quality level.

The adequacy of education has several definitions. From the point of view of system inputs, suitability refers to the number of teachers required to perform a certain task or to the skills that can be performed using specific resources (Myers, J., Silverstein, J. (2002) calculation of the cost of a suitable education in Montana in 20012002 using the Professional Judgment Approach, available at http://wwwmtsba.org/study/Final\%20Rep ort.pdf, accessed 20.01.2020). Another definition regards adequacy as achieving a certain level of student performance in standardized national assessments (Haveman, M. (2004) Determining the Cost of an Adequate Education in Minnesota: Implications for the Minessota Education
Finance System, available at http://www.mntax.org/cpfr/education.pdf).

From the perspective of suitability, a model that identifies a certain required level of the amounts with which the education is funded offers only a starting point or a lower limit on the value of these funds.

Research (Norman, J. (2002) Funding our Future - An Adequacy Model for Wisconsin School Finance, Institute for Wisconsin Future, p. 26) has identified a number of steps that need to be taken to determine the need for funding from the perspective of adequacy, namely:

- $\quad$ Setting quality standards;

- Determining the resources needed for schools to meet the previously established standards;

- The monetary quantification of resources for determining the need for budgeted expenses;

- Establishing the ratio between the level of expenditures and the available funds: in case the level of necessary expenditures is much higher than the available funds, it is necessary either to revise the standards or to adjust the level of expenditures in time to support the appropriate level of rewards.

There are two fundamental questions related to the conceptual adequacy of education: what is the amount of money that allows a school to provide its students with an adequate education and how the resources available in schools can be distributed so that all students receive an adequate education regardless of the circumstances in which the education process takes place.

Two categories of costs can be identified: costs related to the provision of educational services in order to meet the educational needs of the population (both general and specific) and costs related to increasing the performance level of students at a certain level, which vary according to the specific needs of students, and depending on the context in which the educational process takes place (Baker, J., 
Green, D. (2010) Politics, Empirical evidence and policy design, in Handbook of Education Politics and Policy. ed. Bruce S. Cooper, James G. Cibulka, Lance D. Fusarelli, pp. 311337). It can be considered that the two categories of costs represent: costs related to the provision of educational services in order to meet the educational needs of the population (both general and specific), these may be related to the system inputs and the costs related to the increase of the performance level of the students at a certain level, which varies according to the specific needs of the students and depending on the context in which the educational process takes place may be related to the outputs of the system.

The factors that influence the structure of the specific costs of education are represented by the needs of the students, the size of the school or the territorial administrative units but also the geographical characteristics of the area in which the educational unit is located.

Difficulties in learning and low results in assessments may be associated with not meeting the needs of students. The needs of students can be differentiated into two categories: basic needs in terms of the educational process and special needs for minorities, students with disabilities or those from poor families.

Costs must identify needs as closely as possible and relate them to the resources needed to meet them.

An example of such special needs of students is that of students from poor families, who do not have access to the same learning experiences or resources that allow them to make the most of what is offered in the school. Under these conditions, the school together with local administrations must provide additional resources to compensate for these differences. A solution would be to employ more qualified staff, smaller school groups, extra-curricular programs financially supported by the Ministry of National Education or by local administrations. There may also be additional costs related to student mobility that may affect the total costs.

Students with disabilities are another example of students with special needs. Differences from a mental, physical or emotional point of view must be eliminated or diminished. Additional funds are needed to reduce or eliminate these differences.

The size of the school units is also an important factor in the evaluation of costs. As long as an education unit operates below the optimum level in terms of number of students and the funds allocated to it are reduced. These aspects can be identified in rural areas where the number of students is low.

The geographical characteristics of the area in which the schools are located can cause differences in costs both in the costs associated with the teaching staff and in the costs associated with the expenses with the goods and services needed for the good educational instruction for each beneficiary of the education.

Concerns can be identified about determining cost estimation models since the 1970 s when trying to estimate costs using a cost regression model of educational system outputs based on estimating the specific costs of reaching a specific level of student performance in reading and mathematics (Garms, WI, Smith, MC (1970) Educational need and its application to state school finance, The Journal of Human Resources, vol. 5, no.3, summer, pp. 304-317). At the same time, equal opportunities in education are defined as the permission granted to all schools to provide at least a minimum educational standard with reasonable financial effort (Garms, WI, Smith, MC (1970), op.cit. page 304).

\section{Methods of General Cost Analysis}

Cost analysis has become an important tool in both performance evaluation and decision making in the education system in the context where the staff in the education system must have an increasing degree of performance with less funds, and at the 
same time need to provide as much tangible evidence as possible of the effectiveness of educational programs.

We can identify two rational reasons for using cost analysis. On the one hand, the existing budgetary constraints, on the other, the educational policy makers and the leaders of the school units that face limited resources.

There are several approaches to cost analysis that answer different types of questions. A cost feasibility analysis can provide useful results when it is necessary to know the cost of a certain educational program or the possibility of implementing it in the context of a budget constraint.

To determine the usefulness or effectiveness of some programs, it is useful to use a cost-benefit analysis, or cost effectiveness or cost utility.

The multitude of terms associated with cost analysis (cost effectiveness analysis, cost benefit analysis, cost utility analysis, etc.) are used as synonyms in specialized literature even though each term represents a different method of analyzing economic information. Even if in practice the differences between the methods of cost analysis can be considered small, the assumptions from which each method starts are different (qualitative or quantitative) and the results are different.

\section{Cost effectiveness analysis}

In order to elaborate decisions, the cost effectiveness analysis is based on a systematic approach to the costs and consequences of their production. As $\mathrm{H}$. M. Levin exemplifies, there are several ways of approaching how the goals of increasing student performance in math and reading can be achieved, for example, such as adopting a new curriculum, additional teacher training, computer-assisted instruction, diminishing the number of students in classes, etc. The cost-effective solution is to identify the costs and effects that their production has on increasing student performance for each chosen alternative, and ultimately choosing which alternative has the greatest impact on increasing student results in standardized tests (Levin, HM (1995) Cost-effectiveness Analysis, International Encyclopaedia of Economics of Education, 2nd ed. Oxford: Pergamon, pp. 381-386).

Both cost-effectiveness and cost-benefit analysis are methods of evaluating the resources used in some alternatives, and quantifying costs. However, unlike the cost and benefit analysis method, only alternatives whose outputs can be quantified monetarily are considered in the cost effectiveness analysis.

The purpose of practicing cost effectiveness analysis is to determine the minimum cost at which an educational program can achieve its objectives and the hypothesis from which the method development started is that each alternative is associated with both different costs and different outcomes. Moreover, cost minimization results in a more efficient use of society resources, which allows the development of other aspects of education.

Prior to carrying out the cost analysis, it is necessary to know the problem for which it is necessary to elaborate a decision, the alternatives considered as well as their potential effects. After the problem is formulated, it is necessary to evaluate the effectiveness of the considered alternatives, in this sense being needed concrete dimensions and measures of the effectiveness. (Table 2.1) Then, formulating alternative programs is the next step that opens the way for evaluating the effectiveness of these alternatives. As a methodology, standard methods of evaluation, or previous results of similar evaluations, can be used. What is important to keep in mind is that efficiency assessment is not synonymous with cost evaluation (T.D., Campbell, D.T. (1979) Quasi-Experimentation. Houghton Mifflin, Boston, Massachusetts).

By definition, the cost of an alternative represents the value of the resources that the company gives up for the alternative to become possible. Thus, the total cost is the representation of social value, and this 
total cost is subsequently broken down and distributed over the entities that make up the educational system.

Cost estimation can be done by analyzing the component elements of the considered alternatives, which involves identifying these components, determining their cost and total cost and analyzing these costs by following a certain decision-oriented evaluation framework. Most alternatives include as workforce components, equipment, materials, deployment areas, etc. The level of detail of these components must be adequate to guarantee the inclusion of all necessary resources and their value. As sources of data for this stage are used interviews, observations or different existing reports.

The effectiveness analysis that follows the previous step must take into account the suitability of the unit of cost expression and the cost payers. Generally, the effectiveness in education is evaluated in relation to the sizes associated with the students (the number of students who...) which naturally leads to the determination of a cost per student, obtained by dividing the total cost by the number of students. Another way to evaluate the effectiveness of education is the effectiveness rates that are based on the average effects of the analyzed programs and on the cost per student, or the use of the marginal cost. The most widely used measure of cost effectiveness is the efficiency rate obtained by reporting cost effectiveness.

The final stage of the effectiveness analysis is that of comparing the alternatives in terms of cost intensity, separated into fixed costs and variable costs, intensity which differs significantly depending on the number of students enrolled in the programs.

The content of the education program is one of the most frequently analyzed areas in terms of effectiveness, followed by the additional training of teachers.

\section{Cost-Benefit Analysis}

Cost-benefit analysis has been defined as a practical way of assessing the desirability of projects, where a long-term and broad vision is needed which involves listing and evaluating all relevant costs and benefits (Perst, AR, Turvey, R. (1965) Cost-Benefit Analysis: A Survey, The Economic Journal, 75, pp. 683-735). The method dates from the early 20th century, and has been extended over time to all areas of public sector investment and beyond. In the area of education, the method was applied to investments in education where it became known as the rate of return analysis (Cohn, E., Geske, T. (1990) The Economics of Education, Pergamon Press).

The cost-benefit analysis must adhere to a number of principles, namely:

- The existence of a common unit of measure;

- The assessment of costs and benefits must present consumer or producer assessments that reflect their current behavior;

- The measurement of benefits is made through market options;

- The gross benefit of increasing consumption is below the demand curve;

- Certain measures of benefits require the evaluation of some component elements of human life;

- Avoid double-summing of costs or benefits;

- Establishing some decision criteria for projects.

If in terms of costs these can be relatively easily identified, the same cannot be said about benefits. Determining the benefits of education starts from a philosophical approach to the purpose of education and the ways in which it can be achieved. Since Greek antiquity, education has been considered as centred on the moral fulfilment of individuals and the welfare of the society in which they live. Recent studies have shown that education contributes both to better performance of individuals in the labour market but also to improving their health, promoting an 
active civic attitude and reducing violence. It has been shown that educated people tend to live longer, the data revealing a strong association between life expectancy and education level. Educated people tend to be more involved in civic activities just as they tend to be happier.

The main output of the educational system is the information and skills transmitted to students, which they will use throughout their life. School is the place where students learn what adults already know, and is the place where knowledge transfer takes place. The content of the learning is determined by the specialized research, the practical needs and the experience of the teachers. Learning and skills development takes place by gathering and evaluating new information that is transmitted to students, which leads to an increase in their intellectual capacity resulting in an improvement in the intelligence level of the population (Husen, T., Tuijnman, A. (1991) The Contribution of Formal Schooling to the Increase in Intellectual Capital, Educational Researcher, 20 (7), pp. 17-25). Through the school, the differences between the different categories of students considered disadvantaged and those who do not fall in this category are reduced.
One child's education contributes to the well-being of others by ensuring a stable and democratic society (Husen, T., Tuijnman, A. (1991) The Contribution of Formal Schooling to the Increase in Intellectual Capital, Educational Researcher, 2007, pp. 17-25). This is why governments invest considerable amounts in education because of the responsibility that the school has for the individual development of students but also for economic and social well-being (Feinstein, L., et al. (2006) What has the Effects of Education on Health?, in Measuring the Effects of Education on Health and Civic Engagement: Proceedings of the Copenhagen Symposium, R. Desjardins and T. Schuller, Eds, OECD, Paris, France, pp. 171-353).

An educational system with a high level of quality and efficiency offers significant benefits to individuals who are aggregated within communities and which in turn generate major social and economic benefits. The dropout rate affects the unemployment and implicitly the consumption of social assistance funds: the crime rate is low among the educated people, as well as the mortality rate.

The synthesis of the main characteristics and particularities of the methods of cost analysis are presented in table 2.2 .

Table 2.2. Particularities of the methods of cost analysis

\begin{tabular}{|c|c|}
\hline Analysis method & Main features \\
\hline Basic cost analysis & $\begin{array}{l}\text { - answers questions about the financial viability of a program } \\
\text { in terms of overall costs } \\
\text { - It is used to describe economic data } \\
\text { - describes distributions to both real and adjusted costs that } \\
\text { are necessary for the implementation of a particular program } \\
\text { - is the most limited form of cost analysis } \\
\text { - does not take into account the benefits of the program } \\
\text { - it is useful in the planning phase of a project but does not } \\
\text { allow comparisons between programs }\end{array}$ \\
\hline Cost feasibility analysis & $\begin{array}{l}\text { - answers questions about the financial viability of a program } \\
\text { - is useful in the elaboration of the decisions regarding the } \\
\text { described economic data } \\
\text { - is used to determine the extent to which a program can be } \\
\text { successfully implemented under the conditions of budgetary } \\
\text { constraints } \\
\text { - allows the evaluation in non-monetary terms (decrease of } \\
\text { the instructional time, increase of the number of students of a } \\
\text { class, etc.) }\end{array}$ \\
\hline Cost effectiveness analysis & - answers the questions related to the effectiveness of a \\
\hline
\end{tabular}




\begin{tabular}{|l|l|}
\hline & $\begin{array}{l}\text { particular program compared to other programs } \\
\text { - allows comparisons between programs especially when the } \\
\text { comparison is made according to a single criterion such as } \\
\text { progress in the results of national assessments on a particular } \\
\text { subject }\end{array}$ \\
\hline Cost-benefit analysis & $\begin{array}{l}\text { - is used to compare programs that may have different } \\
\text { purposes or structure } \\
\text { - Cost is defined in monetary terms }\end{array}$ \\
\hline Cost utility analysis & $\begin{array}{l}\text { - allows comparisons between educational programs with } \\
\text { different measures of outputs, using conceptual utility } \\
\text { - the cost is not necessarily defined in monetary terms } \\
\text { - the definition and operationalization of the notion of utility } \\
\text { is made in relation to the beneficiaries of the information } \\
\text { provided } \\
\text { - is a subjective method of evaluation }\end{array}$ \\
\hline
\end{tabular}

\section{Methodology Specific to the Analysis of Costs in Education}

The analysis of the costs generated by the educational system implies the completion of a series of stages that we present in the following:

\section{a. Defining the specific parameters of the evaluation}

When evaluating an educational program, evaluators should consider the level at which the program is feasible and ensure that the assessment is conducted in a prudent and realistic manner. For this purpose, it is necessary to define the parameters of the evaluation taking into account the available resources, the information needs as well as the nature and number of outputs related to the program. Depending on these parameters, it can be determined which method of cost analysis is appropriate. Determining the appropriate method must go through the following steps (Levin, H.M., McEwan, P.J. (2001) Cost-Effectiveness Analysis: Methods and Applications, Thousand Oaks, Ca, Sage Publications):
- Formulating specific questions for evaluation;

- Determining the suitability of an economic evaluation;

- Selection of alternative evaluation programs;

- Identification of the beneficiaries of the evaluation results and their informational needs;

- Selecting the most appropriate cost analysis method.

\section{b. Formulation of research-specific questions}

In order to determine the cost analysis form, it is necessary to clearly formulate the questions to which the research undertaken must provide an answer. In this way, it is possible to effectively plan the collection of the data needed for the study, and depending on the nature of these questions, the most appropriate form of cost analysis can be determined which can answer these questions.

Table 2.3 presents some specific questions for the evaluation of the educational programs as well as the methods of analyzing the most appropriate costs. 
Table 2.3: Choosing cost analysis methods in relation to research questions

\begin{tabular}{|c|c|}
\hline Evaluation/research questions & Forms of cost analysis \\
\hline $\begin{array}{c}\text { What is the cost of the program and } \\
\text { what is the cost distribution? }\end{array}$ & Fundamental cost analysis \\
\hline $\begin{array}{c}\text { Can the program be implemented } \\
\text { under budgetary constraints? }\end{array}$ & Cost feasibility analysis \\
\hline $\begin{array}{c}\text { Which program offers the highest } \\
\text { efficiency at the lowest costs? }\end{array}$ & Cost effectiveness analysis \\
\hline $\begin{array}{c}\text { Which program offers the most } \\
\text { benefits at the lowest costs? }\end{array}$ & Cost-benefit analysis \\
\hline $\begin{array}{c}\text { What is the program with the highest } \\
\text { utility and lowest costs? }\end{array}$ & Cost utility analysis \\
\hline
\end{tabular}

Source: own systematization

c. Determining the adequacy of the economic evaluation of the educational programs

The adequacy of the economic evaluation of the educational programs must be interpreted in terms of feasibility and usefulness. Even if any educational program can be subjected to a cost analysis, it is not always appropriate to evaluate the economic education of program outputs. Evaluation may not find its usefulness when its likely outcomes are no greater than the costs of performing that evaluation (Scriven, M. (1974). Evaluation Perspectives and Procedures. In JW Popham (Ed.), Evaluation in Education: Current Applications Berkeley, CA: Mc(utchan).

\section{d. Selection of alternative programs used in the evaluation}

After formulating questions and choosing the most appropriate method of cost analysis, it is necessary to identify a benchmark for comparing the results of the evaluation. Thus, it is necessary to identify a large number of programs from which a reasonable subset will be chosen for analysis (Hopfenberg, W.S., Levin, H.M., Chase, C., Christensen, S.G., Moore, M., Soler, P.L., et al. (1993). The Accelerated Schools Resource Guide. San Francisco: Jossey-Bass).

\section{e. Determining the limits of the evaluation}

The limits or boundaries of the evaluation can be identified considering the nature of the program or the nature of the policies related to it, determined by the initiator of the program (the ministry of education, the school inspectorate, the municipality, etc.). The main limits can be imposed by time, context and the group of beneficiaries of the evaluation.

\section{f. Identification of the beneficiaries of the evaluation results}

Identifying the beneficiaries of the evaluation is one of the most important steps in defining the purpose of performing a cost analysis. Depending on the number of these beneficiaries and their decisionmaking power, the depth of the resource evaluation is established, which may vary depending on different parameters.

\section{g. The actual cost analysis}

After defining the parameters of the evaluation, the analysis of the costs represents the process of collecting and organizing the information about the resources necessary for the implementation of an educational program or an educational policy (Barnett, WS, \& Escobar, CM (1990). Economic Costs and Benefits of Early Intervention. In SJ Meisels \& JP Shonkoff (Eds.), Handbook of Early Childhood Intervention, New York: Cambridge University Press, pp. 560-582). Cost is defined as the value of all the resources to be used by a program and which can be allocated to it (Levin, H.M., McEwan, P.J. (2001) op.cit).

Regardless of the form of cost analysis used, it involves more than just cost 
accounting or budget analysis. Performing a simple budget analysis is not appropriate for the cost analysis because within the budgets all the information regarding the total costs involved by a program, such as donations, volunteering services, etc. is not specified. Also, the budgets are made up of a period of one year, which may be shorter than the period of the development of an educational program and most often reflects the way of the distribution of expenses, at the expense of highlighting the way of spending the available funds.

\section{Conclusion}

The reporting of the expenses in education is carried out by categories of expenses.

A traditional approach to the way in which education expenses are reported is by category of expenses: expenses with staff in education, expenses with auxiliary staff, material expenses, etc. This type of approach can be considered effective when it comes to a simple entity, and it has been used until the role of education has been extended from providing simple instruction to providing social services. Thus, there was born the need to report expenses by functional categories: instruction, educational support, administration, other operations, etc. Another cause that led to the need to differentiate the expenditure by certain categories in order to understand them was the recognition of certain categories of population with special needs, such as students with deficiencies, students from economically or socially disadvantaged families, minorities and so on. Thus, the users of financial information specific to the pre-university education system (directors of educational units, persons involved in the elaboration of educational policies, taxpayers, parents) have focused their attention on understanding how the amounts allocated to education are spent on general educational activities, special education, vocational education, education of children with special abilities or primary education. The interest of these users of information is also related to the benefits generated by spending the amounts allocated to education, reflected in the students' performances or social benefits.

Reporting the data related to the specific expenses of the pre-university education system on objects was thus useful until the complexity of the educational and social policies increased. At present, the reporting of expenses by categories of objects (salaries and related contributions, suppliers, materials) is important only in the context of the functions served (educational, administrative, support activities). In order to evaluate the performance or productivity of the preuniversity education system, however, it is necessary to establish how the allocated resources are organized to ensure the provision of specific services.

The determination of a model for the allocation of resources on educational areas must start from useful and consistent data. One of their main dimensions has to be the comparability of the data, a unitary reporting system that is based on common standards and definitions consistent in time and space. Also, in order to ensure the usefulness of the information, the data related to the resource allocation templates must contain useful information to the social and educational policy makers whose task is to determine new ways to improve the performance and productivity of the education system. All these arguments justify the need to classify, organize and measure resources in a way that helps to understand the impact they have on the outputs related to the education system.

\section{References}

- $\quad$ Andrews, M., Duncombe, W., Yinger, J. (2002) Revisiting economies of size in American education: are we any closer to a consensus? Economics of Education Review, no. 21.

- Baker, J., Green, D. (2010) Politics, empirical evidence and policy design,in Handbook of Education Politics and Policy ed. Bruce S. Cooper, James G. Cibulka, Lance D. Fusarelli. 
- $\quad$ Barnett, W. S., \& Escobar, C. M. (1990) Economic costs and benefits of early intervention In S. J. Meisels \& J. P. Shonkoff (Eds.), Handbook of early childhood intervention, New York: Cambridge University Press

- Cohn, E., Geske, T. (1990) The economics of education, Pergamon Press

- $\quad$ Feinstein, L., et al. (2006) What are the Effects of Education on Health, in Measuring the Effects of Education on Health and Civic Engagement: Proceedings of the Copenhagen Symposium, R. Desjardins and T. Schuller, Eds, OECD, Paris, France.

- Garms, W.I., Smith, M.C (1970) Educational need and its application to state school finance, The Journal of Human Resources, vol. 5, no.3.

- Haveman, M. (2004) Determining the Cost of an Adequate Education in Minnesota: Implications for the Minessota Education Finance System

- Husen, T., Tuijnman, A. (1991) The Contribution of Formal Schooling to the Increase in Intellectual Capital, Educational Researcher

- Jennifer L. White, Craig A. Albers, James C. DiPerna, Stephen N. Elliott,

- Thomas R. Kratochwill, and Andrew T. Roach, Cost Analysis in Educational
Decision Making: Approaches, procedures and Case Examples,

- Levin, H.M. (1995) Cost-effectivness Anaysis, International Encyclopedia of Economics of Education, 2 ed. Oxford:Pergamon

- Levin, H.M., McEwan, P.J. (2001) Costeffectiveness analysis: Methods and applications, Thousand Oaks, Ca, Sage Publications

- Myers, J., Silverstein, J. (2002) Calculation of the cost of a suitable education in Montana in 2001-2002 using the Professional Judgement Approach

- $\quad$ Norman, J. (2002) Funding our Future An Adequacy Model for Wisconsin School Finance, Institute for Wisconsin Future.

- Picus, L.O. (2000) Adequate Funding, în About School Spending: American School Board Journal,

- Văcărel I., Anghelache Gabriela, Bistriceanu Gh.D., Moșteanu Tatiana,

- Bercea F., Bodnar M., Georgescu F., Public finances, second edition, Didactic and Pedagogical Publishing House, RA, Bucharest, 1999 The law 1/2011 - The National Education Law 